\title{
Workshop on Practical Applications of Remote Sensing to Timber Inventory
}

\author{
September $26-28 / 79$ \\ Edmonton, Alberta
}

\section{Abstracts and Summaries}

\section{Methods of Acquiring, Interpreting and Processing Landsat Data for Use in Forestry}

\author{
R. V. Quenet
}

Canadian Forestry Service

Pacific Forest Research Centre Victoria B.C.

LANDSAT imagery has placed a new tool, which can be used in forest classification, in the hands of foresters. It can be used as a supplement to aerial photography or in place of aerial photography where low resolution data are acceptable. The advent of LANDSAT imagery is most timely as its incorporation into conventional forest inventories can do much to alleviate current deficiencies and improve future forest inventory statistics.

Satellite data and digital image analysis systems are described, practical applications of LANDSAT data are discussed and selected examples of its use in forest management and inventories are presented. These include large area planning, updating existing inventories to reflect harvesting, forest fires and new roads, reconnaissance inventories, forest inventory, forest fire management and detection of forest insect and disease damage.

As digital image analysis and satellite technology advance, and their use become more widespread, we can expect significant improvements and new applications of satellite data to forest inventory.

\section{Colour Infrared Aerial Photography and Its Use in Forestry \\ J. Clhlar, C. Goodfellow}

Application Division, Canada Centre for Remote Sensing Ottawa, Ontario

and R. G. Dixon

Intera Environmental Consultants, Ottawa, Ontario

This paper reviews the state-of-the-art in applications of colour infrared (CIR) aerial photography to problems in forest inventory and management. The CIR film characteristics, acquisition and processing are briefly reviewed, and a list of Canadian airphoto companies which acquire CIR photography is presented. Previous applications to timber inventory, fire burns mapping, and to forest damage assessment are reviewed with special emphasis on the use of small scale photography. The costs of CIR, normal colour and black-and-white photographs for a unit-area coverage are compared.

\section{Some Practical Uses of Remote Sensing in Forest Industry \\ P. Gimbarzevsky \\ Canadian Forestry Service \\ Environment Canada \\ Ottawa, Ontario}

Forest industry has played an active role in the development of airborne remote sensing in Canada and aerial photography is now a widely accepted technological tool for the acquisition of forest resource data. In practical application the stereoscopic analysis of black and white and colour aerial photographs is accepted as a rapid, accurate and economic survey method to provide essential information required in logging operations, reforestation, forest engineering or environmental assessment.

This paper describes the ápplication of airphoto analysis techniques and extraction of quantitative and qualitative information of forest cover, physical characteristics of forest land, water resources and significant site-specific features, associated with the operating area. Selected examples demonstrate the usefulness of medium and large scale aerial photography in various phases of forestry operations.

\section{Large Scale Photography for Forest Inventory Problems and Limitations}

\author{
A. Jano \\ Surveys and Mapping Branch \\ Ontario Centre for Remote Sensing \\ 880 Bay Street, Toronto, Ontario \\ M5S 1 Z8
}

Several investigators developed successful methods and systems for taking and analyzing large scale photography for inventory purposes. The methodology being developed by the Ontario Centre for Remote Sensing is still in the research stage. The results so far indicate specific areas where improvement is needed before practical applications may be considered. Aside of photogrammetric problems, it seems that the parameters of the $\mathrm{DBH}$ estimator are stand specific and vary considerably from plot to plot within the same stand. Photographic and ground data collected during the past two years is analyzed to demonstrate this problem and determine its extent.

\section{Adaptation of Large-Scale Photography to Alberta's Provincial Forest Inventory Program}

\author{
A. H. Aldred \\ Dendron Resource Surveys Ltd. \\ Ottawa, Ontario
}

Following the demonstration of the capabilities of large-scale photography as an alternative means of collecting sample plot data for timber inventory purposes, the Alberta Forest Service decided to integrate the new technology into their ongoing inventory program. The integration of the techniques involved required considerable effort to clearly define the user needs, to accommodate and take advantage of existing data and data from other sources and to adapt the peculiarities of the large-scale photo approach to the current inventory procedures and requirements of Alberta's computer-based inventory compilation system. The adaptations involved are to be presented.

\section{Wing Tip Camera for Sampling Photography P. G. Williams \\ Integrated Resources Photography Ltd. Vancouver, B.C.}

Integrated Resources Photography has developed a large-scale photography system utilizing $70 \mathrm{~mm}$ Vinten cameras installed in the wing tips of a light aircraft. Compared with single camera systems exposed sequentially, the wing tip configuration exhibits some advantages for forest inventory sampling. A description of the system and its performance characteristics will be discussed. 
The Large-Scale Photo Sampling System at The Northern Forest Research Centre

\section{L. KIrby and R. J. Hall}

Environment Canada

Canadian Forestry Service

Northern Forest Research Centre

Edmonton, Alberta

A description and evaluation of a low-cost aerial camera and interpretation system assembled at NFRC is presented. The camera system consists of a Honeywell radar altimeter, two 70-mm Vinten aerial cameras and an intervalometer. Height of aircraft above ground is recorded digitally on each exposure taken. Studies have shown that on average, the altimeter is within $\mp 3 \%$ of actual altitude in open and timbered areas combined for the $45-600 \mathrm{~m}$ altitudinal range. Over forested areas, timber bounce may occur and calibration may be necessary to better estimate desired parameters.

The interpretation system consists of a Hewlett-Packard desktop computer interfaced to a Carl Zeiss-Jena Interpretoskop, with a parallax measuring device and digitizer. Computer programs have been written to facilitate speedy compilation and summarization of the variables measured. The system has been applied to timber inventory in the measurement and estimation of tree heights, diameters and volumes; and in the estimation of forest residues, regeneration stocking and wood pile volumes in millyards.

\section{Application of Large-Scale Fixed-Base Aerial Photography with \\ Helicopters to Forest Inventory in British Columbia}

\section{H. Bradatsch}

Inventory Branch

Ministry of Forests

Province of British Columbia

Victoria, B.C.

The fixed-base photographic system described in this paper was developed by the Inventory Branch of the Ministry of Forests. Government of British Columbia for forest stand classification and sampling. The system consists of twin Hasselblad MK70 $70 \mathrm{~mm}$ cameras mounted at a fixed distance apart on an aerial camera platform attached to the tie down (jack points) of the helicopter fuselage.

Large-scale stereo pictures are used to identify the species composition of forest stands and to obtain measurements of individual trees and stands, such as tree height, crown width, number of stems and crown closure.

An example of the application of the system in British Columbia is given together with the relevant statistical analysis that demonstrates the accuracy of the methodology.

\section{Transfer of Space-Age Technology to Forest Inventory in British Columbia; Problems and Solutions

$$
\text { F. Hegyi }
$$ \\ Inventory Branch \\ Ministry of Forests \\ Province of British Columbia \\ Victoria, B.C.}

During the past two decades, forest inventory in British Columbia has consisted mainly of classification with the aid of conventional vertical aerial photographs and ground sampling. In 1978, the Inventory Branch of the Ministry of Forests, Government of British Columbia, initiated a major upgrade to the inventory system. The technological changes that have been implemented include the refinement of the classification system, the introduction of a multiphase sampling methodology combined with photo mensuration, the acquisition of a computerized mapping and data management system, and the use of satellite image analysis.

The introduction of the new technology created numerous problems, especially in the areas of technical and academic training, im. plementation of shift work, and general personnel matters.

This paper contains brief discussions involving some of these problems and their immediate and long-term solutions.
A Test of Small Scale Aerial Photo Susceptlbility Ratings for Southern PIne Beetle In East Texas

\author{
G. N. Mason \& J. E. Howard \\ School of Forestry \\ Stephen F. Austin State University \\ Nacogdoches, Texas
}

Discriminant analysis of infested and noninfested sample data gave a predictive model for susceptibility to Southern Pine Beetle attack. Parameters used were host basal area, average height, and topographic position. A Chi-square test of predicted results against independent attack data was significant at the $95 \%$ level.

\section{Nested Classification}

A Five Stage Nested Sampling Design

\section{G. Hazenberg}

Lakehead University

Thunder Bay, Ontario

and

W. M. Cheliak

Department of Forest Science

University of Alberta

Edmonton, Alberta

The five stage sampling design is generalized from the three stage nested sampling design as presented in standard texts on experimental designs. This paper can be considered as a supplement to these books. The paper demonstrates the structural model and the necessary calculations to be performed for easy adoption in a computer algorithm. The required sums of squares are derived. Without derivation, the standard errors, required for testing observed differences, are presented. An example of the application of the five stage nested classification is included as well.

\section{Provinclal Forest Inventories - Techniques and Development \\ G. M. Bonner \\ Petawawa National Forestry Institute Canadian Forestry Service Ottawa, Ontario}

Data on Canada's forest resources are obtained almost ex clusively from provincial forest inventories. Developed over the last 35 years, the procedures used in these inventories are quite similar. One exception is the inventory used in Ontario, which relies on the measurement of stand parameters applied to yield tables for the estimation of volume and other attributes. Other minor differences are found in the inventories of Newfoundland and Nova Scotia.

Until recently, the only major change in procedures was the introduction of point sampling. Now, changes are occurring more rapidly. This results from the availability of more sophisticated sampling designs (3-P, SPR), improved technology (computers and computerized systems, remote sensing), and the need to reduce the cost of field work.

In the future, changes are likely to continue: more detailed data will be necessary for intensive forest management, new types of data (biomass) will be requested, and new technology (Landsat) will become operational.

\section{Changing Technology in the Saskatchewan Forest Inventory}

\section{J. A. Benson}

Dept. of Tourism and Renewable Resources Room 300, Provincial Office Building

Prince Albert, Saskatchewan

The Saskatchewan Forest Inventory consists of maps and estimates of standing timber by species and size classes, within stratifications identified from aerial photographs. Recent technological advances have made it possible to improve both the 
quality and the method of presentation of inventory data. The process of incorporating some of these changes into the Saskatchewan Forest Inventory will be discussed in three parts:

A. Mapping: in the increasing use of digital computers in the storage and manipulation of map data.

B. Fleld Data Requisition: by incorporation of $3 P$ sampling techniques into the collection of field data, and the adoption of large scale photo sampling techniques in the Reconnaisance Forest Zone.

C. Data Processing: by increasing flexibility in the selection and presentation of inventory data, and the introduction of growth simulation into the forest inventory.

The present and proposed systems and procedures, as well as future trends in the inventory process, will be discussed in each part.

\section{The Use of Medium and Large Scale Photography in Alberta's Timber Inventory}

\section{J. J. Lowe}

\section{Department of Energy and Natural Resources \\ Alberta Forest Service \\ Edmonton, Alberta}

Alberta's Phase 3 forest inventory gathers more information than ever, including stand age and site class, through photointerpretation of quality 1:15 000 MIR photography supported by much ground truthing.

Volume sample plots can be measured accurately on the ground, also in the office using large scale photographs. Data from both sources can. be handled by one cruise compilation computer system.

\section{A New Approach to Forest Inventory Using Remote Sensing}

F. Hegyi

Inventory Branch

Ministry of Forests

Province of British Columbia

Victoria, B.C.

The Inventory Branch of the Ministry of Forests, Province of British Columbia, has developed a new approach for forest inventory using remote sensing. The system is based on a combination of multi-stage and multi-phase sampling. The land is stratified on small-scale (1:20 000) aerial photographs. About $10 \%$ of the strata is covered with large-scale (1:200-1:1000) $70 \mathrm{~mm}$ photographs and six fixed-radius plots are selected in each stratum for primary samples. A sub-sample of these strata are also examined on the ground for detailed inventory measurements and the primary sample estimators are adjusted through double sampling. Secondary sample units are further sub-sampled in a representative manner for growth, decay and waste.

The inventory maps are processed by an Interactive Graphics Design System and a Data Management and Retrieval System. Satellite image analysis is used mainly for updating changes and for optimizing the application of supplementary aerial photography.

\section{A Discussion Paper on the Transfer of Remote Sensing Technology \\ V. G. Zsilinszky \\ Ontario Centre for Remote Sensing Ministry of Natural Resources Toronto, Ontario}

It is the final step in the fulfilment of the mandate of the Ontario Centre for Remote Sensing to transfer technology and techniques to discipline-specific practitioners in government, education and the private sector. This paper considers the criteria according to which technology may be selected for transfer and the means by which the transfer of data acquisition and interpretation methodologies could be effectively accomplished. Finally, the paper describes the necessity of developing an operational market for remote sensing services, and forecasts how technology transfer will proceed in Ontario.

\section{The Transfer of Large Scale Photo Technology in Alberta and Observations}

\section{J. J. Lowe}

\section{Department of Energy and Natural Resources \\ Alberta Forest Service \\ Edmonton, Alberta}

The development of large scale photography as an operational substitute for ground plots in timber cruising is the successful case history described, with emphasis on the problems encountered. Less successful examples and technological gaps are mentioned.

The paper suggests that $R \& D$ is inadequate and lacks direction, although inventory has fared better than some other forestry specializations. Operational agencies have poor research liaison and do not adequately develop the technical potential of their own staff.

\section{Technology Transfer}

Provincial Remote Sensing Centres

\section{Bricker}

Alberta Environment

Alberta Remote Sensing Centre Edmonton, Alberta

The problem in transferring remote sensing technology from research and development agencies to user agencies and in dividuals is largely lack of communication insuring wide distribution of information.

The technology must be practical, current, and readily available throughout the country to users and potential users.

The provincial remote sensing centres within the national program on remote sensing are the key distribution points for the transfer of technology. The Alberta Remote Sensing Centre has successfully transferred remote sensing information from research and development agencies to operational agencies.

\section{Multistage sampling: What's It All About? \\ S. J. Titus \\ Department of Forest Science University of Alberta}

Basic ideas of multistage sampling are discussed in nontechnical terms by answering a number of questions which help us to focus on key concepts. What is multistage sampling? When is it useful? How do we use it? How does it relate to other sampling techniques? How do we decide on an appropriate sample size and allocation? What shortcomings are associated with it? The objectives of the presentation are to:

1) outline the essential elements of multistage sampling

2) illustrate its use with simple examples, and

3) relate it to other common sampling techniques.

\section{Applications of Multistaged and Multiphased Timber Inventories}

\section{L. Kirby}

Environment Canada Canadian Forestry Service

Northern Forest Research Centre Edmonton, Alberta

A review of the first Canadian test of multistage sampling with digital classification of Landsat imagery, interpretation of smallscale color IR aerial photography and large-scale photo sampling to estimate softwood timber volumes is presented. This test in the boreal forest region (B-6 indicates that there would be a $66 \%$ reduction in the variance of the softwood volume estimate when multistage sampling is used instead of random sampling. The approach was applied by Simpson Timber Co. on their lease area in Alberta.

A new project in cooperation with the forest service of the North West Territories now has more emphasis on a multiphased ap- 
proach and a hierarchical information system. A test area approximately 2 million ha in size (1-1/2, 1:250,000 map sheets) has been selected. Summer and winter Landsat scenes of the test area are being enhanced and digitally classified on the ARIES system in Ottawa for the production of thematic maps. Approximately 500 line miles of color I.R. at a scale of 1:25,000 was obtained for development of training areas for the thematic maps. The corrected thematic maps, based on the digital classifications of Landsat imagery, aerial photography and field knowledge, will be digitized and each polygon decribed by a hierarchical coding system. This will provide a data base that may be refined, corrected and updated with a micro computer map information system (MIS).

\section{Application of Temporal Landsat Forest Digital Data to Yukon Information Retrieval System Using Aries}

\author{
Y. J. Lee \\ Environment Canada \\ Canadian Forestry Service \\ Pacific Forest Research Centre \\ Victoria, B.C.
}

This paper describes the usefulness of temporal Landsat forest digital data as input to Yukon RRAMS. an information retrieval system for renewable resource and management statistics.

The temporal Landsat MSS data for a portion of Ecoregion 5 were enahnced to bring out emphasis on (1) softwood, (2) hardwood and (3) bogs. The usefulness of these enhanced images were evaluated using ground truth data.

The results of unsupervised classification were used to compare with those of the supervised classification. The results of the supervised classification were geometrically corrected and referenced to the UTM grid cells. Summaries of percentage occupancy in each UTM grid cell by forest land classes are available for direct input into the Yukon RRAMS data base. The forest land classes include softwood, hardwood, regeneration or young growth, shrub land, alpine water, urban and others.

\section{Forest Cover Type Classification from Landsat Data on Quebec Northshore}

\section{J. Beaubien}

Laurentian Forest Research Centre Canadian Forestry Service

Department of the Environment Sainte-Foy, Quebec G1V 4C7

This paper summarizes a three year project undertaken in the spring of 1978 , on Québec Northshore, to classify forest types over roughly 80000 square miles $\left(200000 \mathrm{~km}^{2}\right)$ in the framework of an ecological land classification preceding hydro-electric installations. An area of $50000 \mathrm{~km}^{2}$ is already mapped using five summer Landsat images of different dates.
The digital data were first enhanced following a 3 principal component method using image enhancement capabilities of ARIES (Applied Resource Image Exploitation System). From a small aircraft or helicopter the resulting color pictures are then used to correlate the various colors to the ground covers. Afterwards supervised classifications were performed. A vegetation mapping at a scale of $1: 125000$ was also done directly by interpreting the enhancements. The following classes were identified and evaluated as components of a pattern in each unit: dense softwood, open softwood, open lichen-softwood, mixedwoods, hardwood, shrub forested heath, lichen forested heath, shrub heath, lichen heath, open peatland, recent burns.

These results and the problems encountered will be discussed. The maps can easily be compared to the synthetic ones produced by Québec's department of lands and forests using conventional aerial photographs. Cost/benefit estimates will be presented.

\section{A Multi-Level Approach to Acquiring Resource Data for Timber Management Planning}

\section{W. R. Dempster}

Alberta Energy and Natural Resources Edmonton, Alberta

and

C. A. Scott

Simpson Timber Company

Whitecourt, Alberta

A program was developed to provide resource information for in dustrial management of $5000 \mathrm{Km}^{2}$ of boreal forest in Alberta. Information needs included: areas and yields of broad timber classes for allowable cut modelling, forest cover and volume data retrievable by location for harvest scheduling, and further detailed information for operational planning in priority areas.

$1: 50,000$ scale false-colour infrared photography was used for interpreting stand characteristics of the entire area. Second stage sampling was by large-scale photography. A proportion of the photo-plots was measured on the ground. Ground plots were destructively sub-sampled. Storage and retrieval of inventory data were computerized. Information needs for operational planning are met by superimposing cover type detail on enlarged photo-mosaics of priority areas and augmenting the inventory data-base by ground and air reconnaissance cruises. Changes occurring between inventories are recorded by a supplementary air photo system.

Note to Readers Regarding Remote Sensing Abstracts and Summaries.

In due course copies of the Proceedings of the Workshop on Practical Application of Remote Sensing to Timber Inventory will be available free, or at nominal cost, from the Northern Forest Research Centre, Canadian Forestry Service, Edmonton, Alberta.

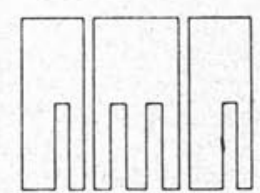

\section{Alan Moss \& Associates Ltd.}

\section{Consultants in Forestry and Forest Industries}

\section{Domestic and International}

\author{
1334 St. Paul Street \\ Kelowna, British Columbia V1Y 2E1 \\ Telephone: (604) 763-4811 \\ Cable: Sylva
}

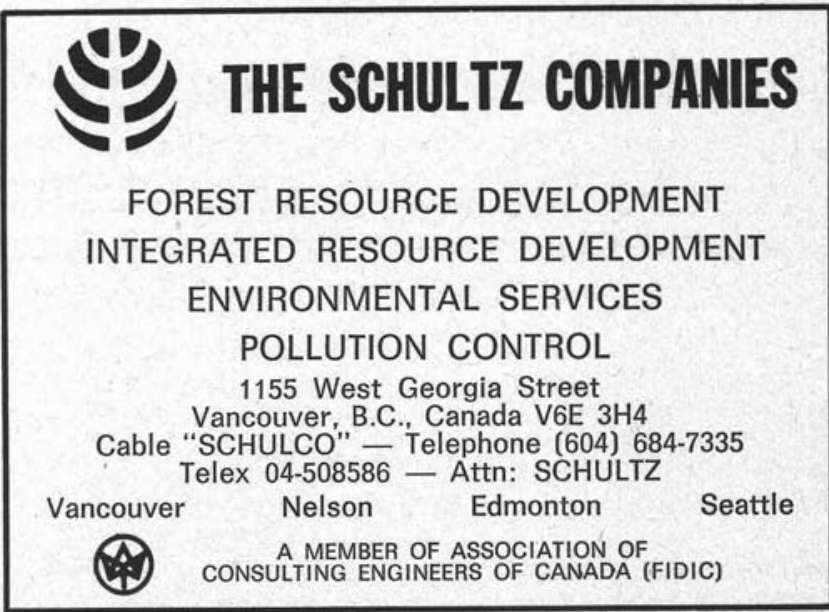

